\title{
Volatile Organic Compounds in the Nation's Drinking-Water Supply Wells-What Findings May Mean to Human Health
}

When volatile organic compounds (VOCs) are detected in samples from drinking-water supply wells, it is important to understand what these results may mean to human health. As a first step toward understanding VOC occurrence in the context of human health, a screening-level assessment was conducted by comparing VOC concentrations to human-health benchmarks. One sample from each of 3,497 domestic and public wells was analyzed for 55 VOCs; samples were collected prior to treatment or blending. At least one VOC was detected in 623 well samples (about 18 percent of all well samples) at a threshold of 0.2 part per billion. Eight of the 55 VOCs had concentrations greater than human-health benchmarks in 45 well samples (about 1 percent of all well samples); these concentrations may be of potential human-health concern if the water were to be ingested without treatment for many years. VOC concentrations were less than human-health benchmarks in most well samples with VOC detections (fig. 1), indicating that adverse effects are unlikely to occur, even if water with such concentrations were to be ingested over a lifetime. Seventeen VOCs may warrant further investigation because their concentrations were greater than, or approached, human-health benchmarks.

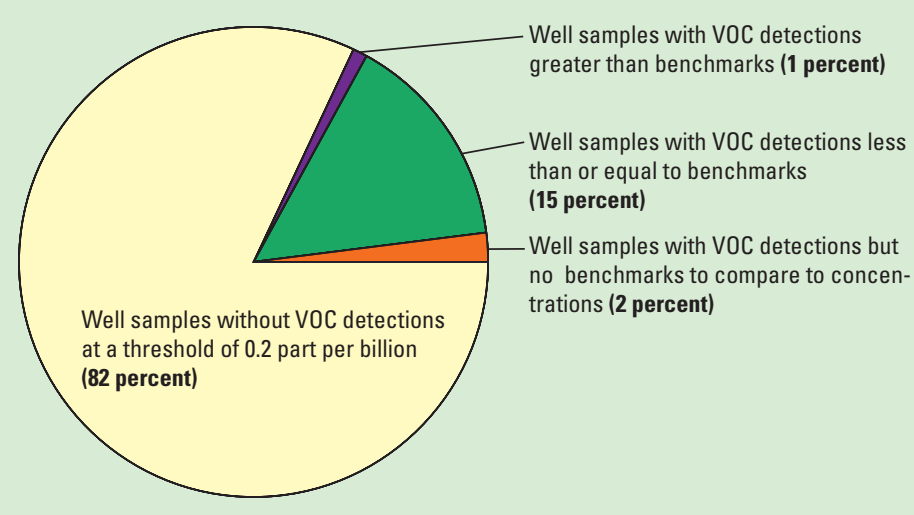

Figure 1. Volatile organic compounds (VOCs) were not detected in samples from 82 percent of the 3,497 domestic or public wells at a threshold of 0.2 part per billion. VOC concentrations were greater than human-health benchmarks in 45 well samples (about 1 percent of all well samples).

\section{Background}

The U.S. Geological Survey's (USGS) National Water-Quality Assessment (NAWQA) Program recently completed a national assessment of volatile organic compounds (VOCs) in ground water (Zogorski and others, 2006; Moran and others, 2006). This Fact Sheet supplements Chapter 4 of Zogorski and others (2006), and focuses on the occurrence of 44 VOCs detected in samples collected prior to any treatment or blending from 2,401 domestic wells and 1,096 public wells (fig. 2). Because domestic and public wells serve as drinking-water supplies, it is important to understand what the VOCs detected in these well samples may mean to human health.

\section{Maximum Contaminant Levels (MCLs)}

MCLs are legally enforceable standards that set the maximum permissible level of a contaminant in water that is delivered to any user of a public water system. MCLs are set as close as feasible to the maximum level of a contaminant at which no known or anticipated adverse effects on human health would occur, taking into account the best available technology, treatment techniques, cost considerations, expert judgment, and public comments (U.S. Environmental Protection Agency, 2006). MCLs were used as benchmarks in this screening-level assessment to evaluate water-quality data in a human-health context. Human exposure from tap water and other pathways was not quantified in this assessment.

VOC concentrations were compared to human-health benchmarks in a screening-level assessment to provide an initial national-scale perspective on the potential relevance of VOC concentrations to human health. The human-health benchmarks used in the screening-level assessment are the U.S. Environmental Protection Agency's (USEPA) Maximum Contaminant Levels (MCLs) and USGS's Health-Based Screening Levels (HBSLs) (Toccalino and others, 2003). Concentrations of regulated VOCs (those with MCLs) were compared to their MCLs, and concentrations of unregulated VOCs (those without MCLs) were compared to their HBSLs, when available (fig. 2).

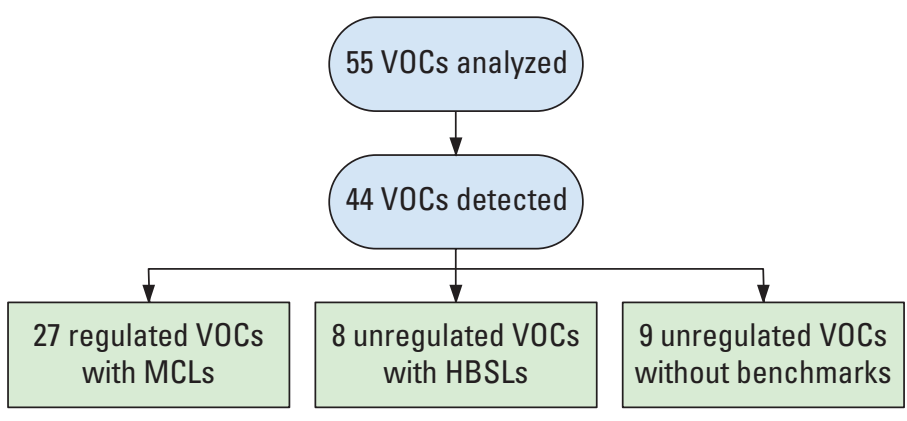

Figure 2. Human-health benchmarks are available for 35 of the 44 volatile organic compounds (VOCs) detected in domestic and (or) public well samples. Human-health benchmarks such as Maximum Contaminant Levels (MCLs) and Health-Based Screening Levels (HBSLs) provide a basis for evaluating VOC concentrations in the context of human health. 


\section{Health-Based Screening Levels (HBSLs)}

HBSLs are benchmark concentrations of contaminants in water that may be of potential concern for human health. HBSLs are nonenforceable guidelines that were developed by the USGS in collaboration with USEPA and others using USEPA methodologies and the most current, USEPA peer-reviewed, publicly available human-health toxicity information (Toccalino and others, 2003). The USGS and its cooperators are continuing to refine the HBSL methodology.

HBSLs are based on health effects alone and do not consider cost or technical limitations. For noncarcinogens, the HBSL represents the contaminant concentration in drinking water that is not expected to cause any adverse effects over a lifetime of exposure. For carcinogens, the HBSL range represents the contaminant concentration in drinking water that corresponds to an excess estimated lifetime cancer risk of 1 chance in 1 million to 1 chance in 10 thousand. HBSL calculations adopt USEPA assumptions for establishing drinking-water guidelines, namely, lifetime ingestion of 2 liters of water per day by a 70-kilogram adult. For noncarcinogens, it also is assumed that 20 percent of the total contaminant exposure comes from drinking-water sources and that 80 percent comes from other sources (for example, food and air). If data are available to quantify the percentage of contaminant exposure that comes from water, then a dataderived percentage is used instead of the default of 20 percent.

\section{How are VOC concentrations compared with human- health benchmarks?}

VOC concentrations in each water sample were compared to MCLs or HBSLs and were expressed as ratios to provide perspective on what VOC occurrence may mean to human health and to help prioritize further investigations. A concentration that is 10fold greater than an MCL or HBSL produces a ratio of 10, and a concentration that is 10-fold less than an MCL or HBSL produces a ratio of 0.1 . A ratio of 1 represents a concentration equal to a human-health benchmark.

Water containing VOCs with ratios greater than 1 may be of potential human-health concern if the water were to be ingested for many years as the primary drinking-water source without treatment. The likelihood for adverse effects generally increases as the VOC concentrations (and ratios) increase. Ingestion of water containing VOCs with ratios less than 1 is unlikely to result in adverse humanhealth effects. VOCs with ratios greater than or equal to 0.1 were identified as those that may warrant further investigation. A variety of ratios may be selected as threshold values to identify contaminants that may warrant further monitoring; using a threshold ratio of 0.1 is consistent with various State and Federal practices (for example, see U.S. Environmental Protection Agency, 2003a).

Assessing the potential relevance of VOC concentrations to human health is more complicated, however, than calculating ratios. NAWQA studies were not designed to evaluate specific effects of VOCs on human health, and the screening-level assessment is not a substitute for a comprehensive risk assessment, which could include additional factors such as the following:

- Length of time a person is exposed;

- Volume of water ingested per day;

- Vulnerability of individuals (for example, children and immunocompromised persons may be more vulnerable);

- Number of contaminants in the water supply (that is, contaminant mixtures);

- Exposure routes such as ingestion and inhalation; and

- Water treatment method, if any.

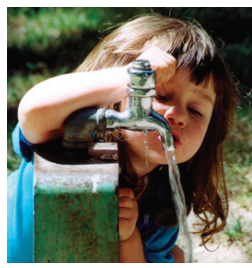

VOC concentrations were seldom greater than human-health benchmarks in domestic and public well samples.

\section{What does it mean when VOC concentrations are greater than human-health benchmarks?}

In this national screening-level assessment, VOC concentrations of potential human-health concern were defined as concentrations greater than MCLs or HBSLs (ratios greater than 1) in samples from drinking-water supply wells. VOC concentrations were greater than MCLs in 45 of the 623 well samples with VOC detections (about 1 percent of all well samples) (fig. 1).

Eight regulated VOCs had concentrations greater than MCLs in one or more well samples (table 1), with maximum concentrations producing ratios of 2 to 30 (fig. 3). These eight VOCs warrant additional monitoring to characterize concentrations in drinking water and to establish trends in their occurrence. The fumigant dibromochloropropane (DBCP) and the solvents trichloroethene (TCE) and perchloroethene (PCE) accounted for the majority of VOC concentrations greater than MCLs in domestic and (or) public well samples (table 1). The potential health effects that may result from exposure to these VOCs at concentrations greater than the MCLs are summarized in table 1. None of the detected unregulated VOCs had concentrations greater than HBSLs.

If water containing VOC concentrations greater than MCLs or HBSLs is ingested, it does not necessarily indicate that adverse human-health effects will occur because there are mitigating factors such as the following:

- Human-health benchmarks are intentionally conservative (protective) and incorporate safety factors and conservative assumptions to account for uncertainty in toxicity information.

- Models used to develop MCLs and HBSLs assume lifetime exposure, whereas actual exposure may be less than a lifetime. In this screening-level assessment, one sample from each well was analyzed for VOCs, and it is unknown whether measured concentrations will remain the same over time.

- All domestic and public well samples were collected at the wellhead (the point at which the water exits the ground) before any treatment or blending that potentially could reduce VOC concentrations. The sampled water may not, therefore, represent the quality of water ingested by the people served by these wells.

The Safe Drinking Water Act (SDWA) applies to water distributed through a public water system, but in this assessment, public wells were sampled at the wellhead prior to distribution. Drinkingwater standards (MCLs) are not violated if VOC concentrations are greater than MCLs in the domestic or public well samples considered in this assessment because these samples are not subject to regulation by the SDWA. 
Table 1. Eight regulated volatile organic compounds (VOCs) were detected at concentrations greater than Maximum Contaminant Levels (MCLs) in domestic and (or) public well samples (ratios were greater than 1). The VOCs are listed in order of decreasing ratios, corresponding to the eight purple symbols on figure 3. Seven of the eight VOCs are regulated as carcinogens, and most may adversely affect the liver.

\begin{tabular}{|c|c|c|c|}
\hline $\begin{array}{l}\text { Compound name } \\
\text { (abbreviation) }\end{array}$ & $\begin{array}{l}\text { Number of samples with } \\
\text { concentrations greater } \\
\text { than MCLs }\end{array}$ & Carcinogen ${ }^{1}$ & $\begin{array}{l}\text { Potential health effects from exposure to } \\
\text { concentrations greater than the } \mathrm{MCL}^{2}\end{array}$ \\
\hline Trichloroethene (TCE) & 15 & yes & Liver problems; increased risk of cancer \\
\hline Ethylene dibromide (EDB) & 3 & yes & $\begin{array}{l}\text { Problems with liver, stomach, reproductive system, or } \\
\text { kidneys; increased risk of cancer }\end{array}$ \\
\hline Methylene chloride & 2 & yes & Liver problems; increased risk of cancer \\
\hline Dibromochloropropane (DBCP) & 14 & yes & Reproductive difficulties; increased risk of cancer \\
\hline Perchloroethene (PCE) & 14 & yes & Liver problems; increased risk of cancer \\
\hline 1,1-Dichloroethene & 3 & no & Liver problems \\
\hline 1,2-Dichloropropane & 3 & yes & Increased risk of cancer \\
\hline Vinyl chloride & 2 & yes & Increased risk of cancer \\
\hline
\end{tabular}

${ }^{1}$ Probable or likely human carcinogen as defined by U.S. Environmental Protection Agency.

${ }^{2}$ Data from U.S. Environmental Protection Agency (2003b).

\section{What does it mean when concentrations are less than human-health benchmarks?}

VOCs were not detected in 82 percent of the samples from 3,497 domestic or public wells in this screening-level assessment at a threshold of 0.2 part per billion. VOC concentrations were less than MCLs or HBSLs in most well samples with VOC detections (fig. 1). Twenty-seven VOCs (19 regulated and 8 unregulated VOCs) had concentrations less than MCLs or HBSLs in one or more well samples, with maximum concentrations producing ratios of 0.9 to 0.000006 (fig. 3). Ingesting water with concentrations less than human-health benchmarks is unlikely to result in adverse human-health effects, even if water with such concentrations were to be ingested over a lifetime.

Seventeen VOCs may warrant further investigation because their ratios were greater than 0.1 ; all 17 are regulated VOCs with MCLs. These 17 VOCs include the eight VOCs with ratios greater than 1 (table 1) and nine VOCs with ratios between 0.1 and 1 (fig. 3, table 2). Additional monitoring for these 17 VOCs allows for analyzing trends in their occurrence and, for the nine VOCs with ratios between 0.1 and 1 , may provide an early indication if VOC concentrations approach human-health benchmarks.

Identifying VOCs with concentrations less than or greater than human-health benchmarks provides useful information about what VOC occurrence may mean to human health, but screening-level assessments have limitations. For example, MCLs and HBSLs generally are developed using toxicity information for single chemicals. However, mixtures of two or more VOCs were found in about 4 and 13 percent of all domestic and public well samples, respectively. The long-term cumulative effects of low concentrations of multiple contaminants on human health currently are unknown. An additional limitation is that HBSLs have not been developed for nine detected unregulated VOCs because of a lack of toxicity information (fig. 2, table 3 ). The potential relevance of the occurrence of these nine VOCs to human health cannot, therefore, be evaluated at this time.

\section{Ratios of maximum concentrations to MCLs or HBSLs for the 35 detected VOCs with benchmarks}

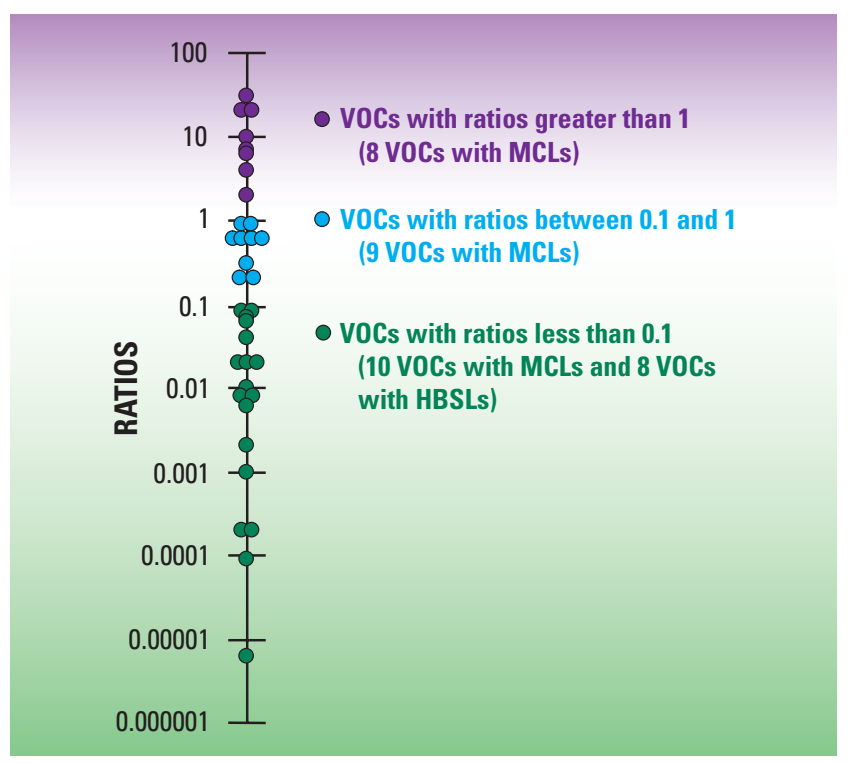

Figure 3. Ratios were less than 1 for 27 of the 35 volatile organic compounds (VOCs) with human-health benchmarks detected in domestic and (or) public well samples. Ratios less than 1 indicate that maximum concentrations were less than Maximum Contaminant Levels (MCLs) or HealthBased Screening Levels (HBSLs). Eight VOCs had maximum concentrations of potential human-health concern (ratios were greater than 1) (see table 1). Seventeen VOCs had ratios greater than 0.1 and may warrant further investigation (see tables 1 and 2). 
Table 2. Nine regulated volatile organic compounds (VOCs) detected in domestic and (or) public well samples had concentrations approaching Maximum Contaminant Levels (MCLs) and may warrant inclusion in future ground-water monitoring efforts. The VOCs are listed in order of decreasing number of samples with concentrations producing ratios between 0.1 and 1 .

\begin{tabular}{lc}
\hline \multicolumn{1}{c}{$\begin{array}{c}\text { Compound name } \\
\text { (abbreviation) }\end{array}$} & $\begin{array}{c}\text { Number of samples with ratios } \\
\text { between 0.1 and 1 }\end{array}$ \\
\hline Chloroform & 10 \\
\hline Carbon tetrachloride & 8 \\
\hline Benzene & 7 \\
\hline 1,2-Dichloroethane & 5 \\
\hline Dibromochloromethane & 3 \\
\hline Bromoform & 2 \\
\hline 1,1,1-Trichloroethane (TCA) & 1 \\
\hline Bromodichloromethane & 1 \\
cis-1,2-Dichloroethene & 1 \\
\hline
\end{tabular}

\section{What actions may be warranted when concentrations are greater than human-health benchmarks?}

If water from untreated domestic or public well samples contains VOC concentrations of potential human-health concern, it does not necessarily indicate that water from these wells should not be ingested, although various responses may be warranted. Prudent responses by water utilities could include limiting human exposure through water treatment such as filtration using granular activated carbon, blending with a less contaminated water source, or using an alternative water supply. Other responses could include identifying and reducing potential sources of contamination, evaluating methods for protecting source waters, and ongoing monitoring to see if concentrations remain at levels of potential concern.

Individuals who receive their water from a water utility can examine the Consumer Confidence Report published by their water utility to determine which, if any, contaminants are present in their water after it is treated, and if so, at what concentrations. Domestic (private) well owners may contact local and State health agencies for information about the characteristics of well water in their area and may have their water tested for contaminants that may be of local potential concern. Additionally, individuals may use in-home water treatment devices designed to remove particular contaminants.

\section{References}

Moran, M.J., Hamilton, P.A., and Zogorski, J.S., 2006, Volatile organic compounds in the Nation's ground water and drinking-water supply wells-A summary: U.S. Geological Survey Fact Sheet 2006-3048, $6 \mathrm{p}$.

Toccalino, P.L., Nowell, L.H., Wilber, W.G, Zogorski, J.S., Donohue, J.M., Eiden, C.A, Krietzman, S.J., and Post G.B., 2003, Development of health-based screening levels for use in state- or local-scale water-quality assessments: U.S. Geological Survey Water-Resources Investigations Report 03-4054, 22 p.

U.S. Environmental Protection Agency, 2003a, Code of Federal Regulations, 40CFR159, Subpart D-Reporting requirements for risk/benefit information: Washington, D.C., revised July 1, 2003, http://www.gpoaccess.gov/ecfr/index.html.
Table 3. Nine unregulated volatile organic compounds detected in domestic and (or) public well samples have no human-health benchmarks. Health-Based Screening Levels could not be calculated for these VOCs because of a lack of available toxicity information. The VOCs are listed in order of decreasing numbers of samples with detections.

\begin{tabular}{lc}
\hline \multicolumn{1}{c}{$\begin{array}{c}\text { Compound name } \\
\text { (abbreviation) }\end{array}$} & $\begin{array}{c}\text { Number of samples with } \\
\text { detections }\end{array}$ \\
\hline Methyl tert-butyl ether (MTBE) & 105 \\
1,1-Dichloroethane & 29 \\
1,2,4-Trimethylbenzene & 9 \\
Chloroethane & 5 \\
tert-Amyl methyl ether (TAME) & 5 \\
Diisopropylether (DIPE) & 4 \\
Ethyl tert-butyl ether (ETBE) & 1 \\
$n$-Butylbenzene & 1 \\
$n$-Propylbenzene & 1 \\
\hline
\end{tabular}

U.S. Environmental Protection Agency, 2003b, Water on tap-What you need to know: Office of Water, U.S. Environmental Protection Agency, EPA 816-K-03-007, http://www.epa.gov/safewater/wot/ $p d f s / b o o k \_w a t e r o n t a p \_f u l l . p d f$.

U.S. Environmental Protection Agency, 2006, Setting standards for safe drinking water: accessed March 27, 2006 at http://www.epa. gov/safewater/standard/setting.html.

Zogorski, J.S., Carter, J.M., Ivahnenko, Tamara, Lapham, W.W., Moran, M.J., Rowe, B.L., Squillace, P.J., and Toccalino, P.L., 2006, The quality of our Nation's waters - volatile organic compounds in the Nation's ground water and drinking-water supply wells: U.S. Geological Survey Circular 1292, 101 p.

\section{By Patricia L. Toccalino, Barbara L. Rowe, and Julia E. Norman}

\section{Contacts for additional information}

\author{
About VOCs in the Nation's ground water and drinking- \\ water supply wells: \\ John Zogorski \\ VOC National Synthesis \\ National Water-Quality Assessment Program \\ U.S. Geological Survey \\ 1608 Mountain View Rd. \\ Rapid City, SD 57702 \\ Phone: (605) 394-3214 Email: jszogors@usgs.gov \\ http://water.usgs.gov/nawqa/vocs/national_assessment
}

\author{
About Health-Based Screening Levels: \\ Patricia Toccalino \\ U.S. Geological Survey \\ 6000 J Street, Placer Hall \\ Sacramento, CA 95816 \\ Phone: (916) 278-3090 Email: ptocca@usgs.gov \\ http://water.usgs.gov/nawqa/HBSL/
}

